\title{
Innovation Vision of the Turkish Construction Industry: A Comparative Qualitative Content Analysis of Strategic Roadmaps
}

Gizem Bilgin, Pinar Bilgin, Irem Dikmen, Talat Birgonul

Middle East Technical University, Ankara, Turkey

\begin{abstract}
Construction plays a crucial role in Turkey's economic development, accounting for nearly 8-9\% of GDP. The growing global competitiveness of Turkish contractors also contributes significantly to the balance of payments of Turkey. It is widely acknowledged that competitiveness of firms depends on national "innovation systems," that is shaped by government policy, and an innovation vision is needed at the industry-level as well as supporting mechanisms such as funding schemes for research and development in the priority areas, and platforms to enable knowledge transfer between various stakeholders. In this paper, we will discuss the innovation vision within the Turkish construction industry, by referring to various construction industry-specific reports. Specifically, we will investigate the vision and conceptualization of innovation in the "Construction Industry Roadmap" as a part of the 10th Development Plan that was prepared by the Turkish Ministry of Development. A comparative study has been carried out between this report and a white paper entitled as "Shaping the Future of Construction: Insights to redesign the industry" that was prepared by the World Economic Forum (WEF) by conducting a content analysis using NVivo. Although the content of two documents in terms of the "drivers" and "enablers" of innovation coincides to a large extent, the innovation was approached in a broader sense considering concepts such as "systemic innovation", "lessons learned", "disruptive innovation", "eco-innovation", "incremental innovation" and "open source innovation" in the WEF's report. Potential benefits of looking at the innovation system from a wider lens will be discussed as well as recommendations for further studies.
\end{abstract}

Keywords: innovation, strategic roadmaps, qualitative, construction.

\section{Introduction}

Construction industry is one of the driving industries in the world economy. It has special importance for a country's economy with its input-output relations with other industries and contribution to employment. Construction plays a crucial role in Turkey's economic development, accounting for nearly 8-9\% of GDP. Turkish construction sector has undertaken an increasing volume of international commitments in recent years. According to the Engineering News Record (ENR) list in 2003, there were just 8 construction companies from Turkey. In 2018, 46 Turkish firms were in the ENR list. As of 2016, the total revenue of the Top 250 International Contractors was 468.12 Billion US Dollars, $5.5 \%$ of which was carried out by the Turkish contractors (Engineering News Record, 2017). According to the 2023 vision of Turkish Contractors Association (TCA) (2011), there are four targets which are;

- To have at least 40 firms in the ENR's Top 225 International Contractors list and increase the share in the global construction market.

- To increase the number of innovative and technology-intense projects and increase their share up to $30 \%$ of all awarded contracts.

- $\quad$ To establish at least 5 EPC contractors operating in international markets.

- $\quad$ To invest at least $1 \%$ of profit in R\&D activities and thereby increase innovation.

It seems that the first target has already been achieved as of 2016. However, there are also ambitious targets which are mainly related with increasing the innovation capability which necessitate deliberate strategies and policies. Innovation is considered to be an important source of competitiveness in international markets. As it has long been recognized as one of the key factors contributing to national economic growth, competitiveness, and higher living standards, industry strategic plans/roadmaps are prepared, and public policy instruments are designed to increase the innovation potential of contractors. Types of innovation vary from the gradual incremental change of current products to revolution, disruption, and reinvention of new industries (Sammut-Bonnici and Paroutis, 2013). Sundbo (2002) states that innovation can be forced by changes in markets and industries and generated independently by the 
company's internal initiatives. The process of innovation is influenced by the decision maker's choice of strategic actions, and as of the last principle; innovation requires internal and external social networks to utilize new ideas and resources. Seadan and Manseau (2001) have reported country-specific observations drawn from case studies of 15 countries to discuss the effectiveness of public policy instruments to foster innovation in the construction industry.

In this paper, we will concentrate on a recent document prepared by the Turkish government to enhance the innovation potential of the Turkish construction industry. In the next section, we will summarize previous efforts carried out by Turkish Contractors' Association to develop strategic roadmaps. Then, the strategic documents that were used in the comparative analysis are briefly explained. Findings from the comparative analysis are reported as well as some conclusions.

\section{Strategic Roadmaps in the Turkish Construction Industry}

One of the pioneering strategic documents prepared for the Turkish construction industry was published by the Turkish Contractors Association (TCA) in 2004. In this document, the excessive emphasis was put on the importance of increasing the competitive capacity of Turkish contractors in the international markets. According to TCA's strategic plan (2004), improving productivity was the key to maintaining and increasing the competitiveness of Turkish contractors. To achieve competitive advantage in the international market, three strategic objectives were determined: enhancing the quality and improving the human capital and physical capital (TMB, 2004). In the physical capital improvement plan, the requirement of innovation for construction companies to maintain their positions in the highly competitive market is highlighted. Moreover, it was mentioned that an effective R\&D network within the industry is needed to support innovation creation $(T M B, 2004)$. It is also worth mentioning that the formation of collaborations and strategic alliances were recommended as a possible solution to the problems in the industry. In the document, although "innovation" was not pronounced directly, the objectives and proposed solutions to existing problems in the industry implied innovative approaches and practices.

In 2011, a workshop was organized by TCA with the participation of different stakeholders, such as contractors, professional managers, senior government participants, financial sector representatives, and academics. In the workshop, it was agreed that the strategic targets which were mentioned in the 2004 strategic plan are still valid. In addition to those, the primary objectives of the Turkish contractors and priority areas were categorized under six main groups as follows:

1. Institutionalization in the sector, collaboration, and improvement of sectoral reputation.

2. Overseas breakthroughs, branding, incentives, and accreditation

3. To solve urbanization problems in the country, improvement of legislation and regulation of the build-sell sector

4. Improvement of the consultancy sector and increasing the use of domestic construction materials in international markets

5. Developing alternative financing methods for infrastructure

6. Enhancing the human capital and R \& D

It is interesting to note that in this document, the word "innovation" was used in combination with "use of advanced construction technologies" and "increasing the R\&D activities and allocating a larger budget for $R \& D$ " was identified as the "strategy" to enhance innovation. There are no specific strategies or actions about how to enhance innovation except increasing R\&D expenditure. It can be concluded that "innovation" become a strategic issue starting from 2010s in the Turkish construction industry. However, no specific strategic and/or action plans were prepared by the government or civil organizations. In the next section, we will investigate the most recent strategic document prepared regarding the Turkish construction industry and compare it with a global strategic report.

\section{A Comparative Study of Strategic Documents considering innovation}

In this study, two strategic documents, which are 10th Development Plan that was prepared by Turkish Ministry of Development (2014) and a white paper "Shaping the Future of Construction: Insights to redesign the industry" that was prepared by World Economic Forum (WEF) (2017), were used to compare innovation vision in the Turkish construction industry and vision in a global roadmap. 


\subsection{Strategic Plan of the Turkish Construction Industry (SPTC) as a part of the 10th Development Plan}

Strategic Plan of the Turkish Construction Industry (SPTC) as a part of the 10th Development Plan is a strategic document that was prepared by the Specialized Commissions and Working Groups that carried out their studies under the Republic of Turkey Ministry of Development. The main objective of the SPTC is to formulate strategies and identify action items for related stakeholders to reach the Vision 2023 targets of the Turkish construction industry. Within the context of the SPTC, the vision of the construction industry was determined by considering the results of a SWOT analysis. In order to realize this vision, seven strategies, and nine strategic programs were determined These strategic programs are "training", "technical consultancy services", "competition", "differentiation of services and collaboration", "expanding abroad", "user-oriented and sustainable built environment", "occupational health and safety", "innovation", and "coordination". Among these strategic programs, innovation is identified as one of the highest priority programs. The key themes that appear in SPTC presented in Table 1 reflect the innovation vision of the Turkish construction industry.

Table 1: Eight Key Themes from SPTC

\begin{tabular}{|rl|}
\hline \multicolumn{1}{|c|}{ Key Themes } \\
\hline 1. & Innovation system \\
\hline 2. & Research and development \\
\hline 3. & Technological foresight \\
\hline 4. & Collaboration \\
\hline 5. & Strategic alliances \\
\hline 6. & University-industry-public cooperation \\
\hline 7. & Innovation culture \\
\hline 8. & Technical consultancy \\
\hline
\end{tabular}

3.2 "Shaping the Future of Construction: Insights to redesign the industry" that was prepared by the World Economic Forum (WEF Report)

"Shaping the Future of Construction: Insights to redesign the industry" (WEF Report) was prepared by a working group consisting of academics, industry leaders and experts in the World Economic Forum (WEF) as a white paper in 2017. In the WEF Report, the aim is to present the outputs of the studies that are carried out by the working groups for creating and analyzing innovative ideas and discussing the possible effects of these ideas and the barriers that may hinder to implement these ideas. In the report, different challenges in six major areas that the construction industry has faced (Table 2) and the innovative solutions to these challenges are presented as separate cases.

Table 2: Challenge Areas Covered in the WEF Report

\begin{tabular}{|rl|}
\hline \multicolumn{1}{|c|}{ Challenge Areas } \\
\hline 1. & Project delivery \\
\hline 2. & Life-cycle performance \\
\hline 3. & Sustainability \\
\hline 4. & Affordability \\
\hline 5. & Disaster resilience \\
\hline 6. & Flexibility, livability, and well-being \\
\hline
\end{tabular}

\subsection{Qualitative Content Analysis}

The commercially available qualitative data analysis software NVivo was used for qualitative content analysis. The steps are summarized in Figure 1. First, both of SPTC and WEF Report are imported to NVivo software. Based on SPTC's context of the innovation program, eight themes are analyzed, and the results are added as initial key themes. Additionally, frequently occurred concepts are searched to evaluate 
accentuated concepts in documents. With the help of Auto Code Wizard in NVivo, details of the WEF Report is gathered about particular themes into a node for further exploration. Auto-coding feature is designed to speed up the coding process for large volumes of textual content. Only the nodes related to innovation are taken from auto-coding outputs, and manual coding process is conducted for further exploration. The aim of manual coding is finding detailed innovation related themes. In this sense, the manual coding process is continued until the main themes and relationships between innovation and themes are reached. After reaching the main themes and their relationships, comparison diagram of strategic documents is drawn using NVivo Project maps option for graphic representation of the different items used to explore and present the connections in the data. As the final process of the flowchart, outputs come from the comparison diagram are interpreted. The process mentioned in the flowchart is examined in detail in the following paragraphs.

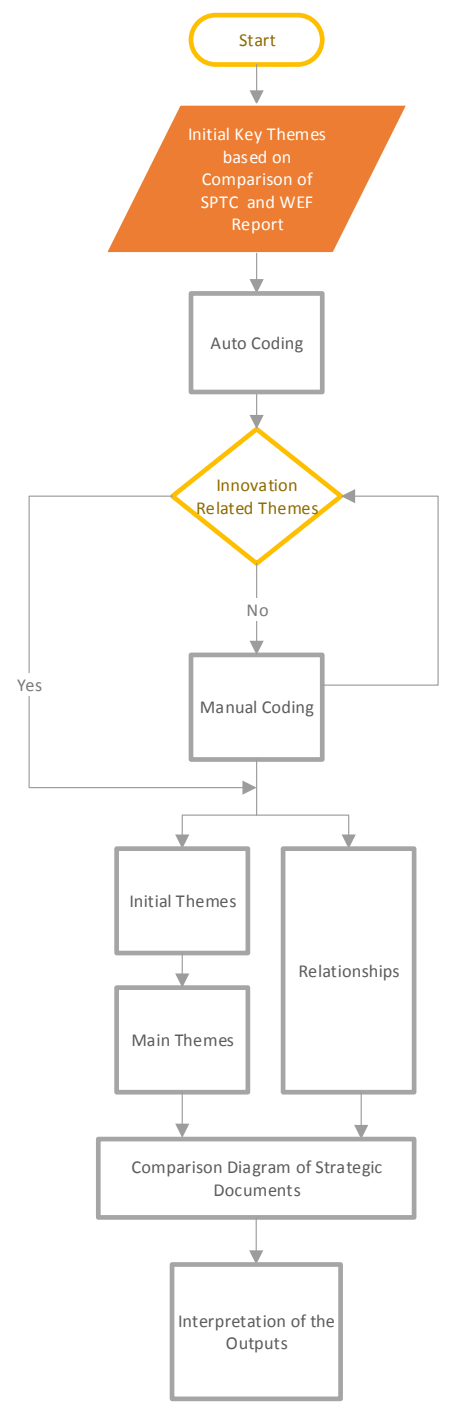

Figure 1: Flowchart of Qualitative Research

In SPTC, eight main steps are mentioned within the context of the innovation program. In the initial step of the content analysis, each of these eight steps was evaluated and determined as key concepts (see Table 1) that will be searched in the WEF Report. By using the "Text Search" option in the software, the occurrence frequency of these concepts was queried. As a result of the text search, it was seen that all the eight key concepts obtained from SPTC are mentioned in the WEF Report. Therefore, these concepts were assigned to both documents as common nodes. Furthermore, both documents were analyzed individually by using 
the "Word Frequency" query to find the frequently occurred concepts so that the accentuated concepts in documents can be understood better. It is worth to note that to have a better result in word frequency query some words that do not contribute to reflect the concepts in the text like auxiliary verbs, some commonly used verbs, conjunctions, and affixes are assigned as stop words in default. Stop words are not received for consideration when the analyses are run. In this study, to get better results, words that are expected to appear in the results due to the concept of research like "construction and project" were also added to stop words

Since the content of the WEF Report is related with insights and innovative ideas to redesign the construction industry, most appeared words in the word cloud are also frequently used words to give insights. As can be seen in the word cloud in Figure 2, in the WEF Report, wide coverage was given to the infrastructure projects. Challenges to the future of construction and the innovative solutions for the potential barriers are mentioned in the WEF Report and they are mainly given around the topic of infrastructure projects. When the WEF Report is scanned, topics such as advancing the outcome of challenging infrastructure projects through project alliancing, life-cycle concepts in infrastructure asset management, creating an inclusive and affordable infrastructure ecosystem, and resilience of transport infrastructure systems are easily recognized. Moreover, it is seen that topics related to life cycle performance, sustainability, affordability, flexibility, liveability, and well-being are mentioned in the WEF Report. Resilience such as disaster resilience, the resilience of transportation systems, and the challenges are other topics that are highlighted. Furthermore, using the word cloud themes connecting with innovative solutions, including the usage of new technologies and materials are seen. When the WEF Report is investigated, eco-innovations in flooring for improved air quality and healthy indoor environments and innovative flooring to meet the aging population challenge are one of the examples that belong to themes found using the word cloud.

With the help of the "auto code" option in NVIVO, the most frequently mentioned concepts in the WEF Report were investigated. However, since this study covers only the innovation concept, only sub-codes under the innovation code were examined. Then, the themes that are related to our study were selected. These themes were created as new nodes and assigned only to the WEF Report in addition to common nodes because these themes are not mentioned in SPTC.

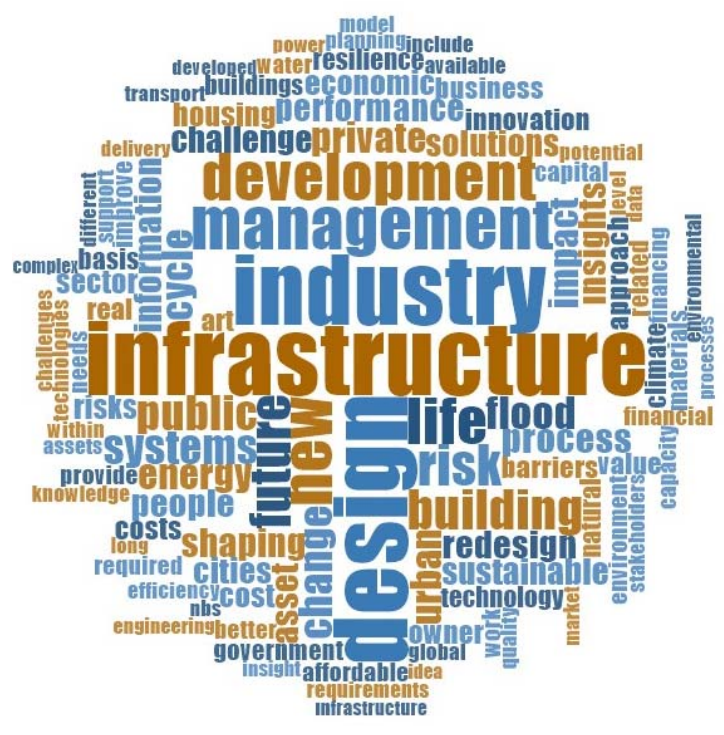

Figure 2: Word Cloud for WEF Report

After determining common and main concepts that are mentioned in both documents and conducting the auto-coding process, to gain insight about other innovation-related concepts mentioned in WEF Report, the word "Innovation" was searched in the report again by using "Text search" option. The results are visualized as a word tree (see Figure 3), which gives the statements just before and after the word "innovation." Since it displays the results as a tree with branches representing the various contexts in which the word or phrase occurs, the word tree helps to create a deep investigation around innovation. The size 
of the font indicates the number of times the word or phrase was found. Furthermore, the software enables to see the wider context of the phrases found in the word tree. In this sense, "innovation" as the root, concepts mentioned related to innovation are shown in the tree. It allows to see the bigger picture related to innovation mentioned in the WEF Report.

As a result of this analysis, it can be seen that the WEF Report gives wide coverage to "Barriers to innovation" and "Innovation and solutions." Innovation types such as systemic and incremental innovation mentioned in the WEF Report were noticed though this word tree easily. Furthermore, the tree helps to observe why WEF Report gives importance to innovation and what can be done "to foster" or "to encourage" the innovation can be observed by the help of this tree.

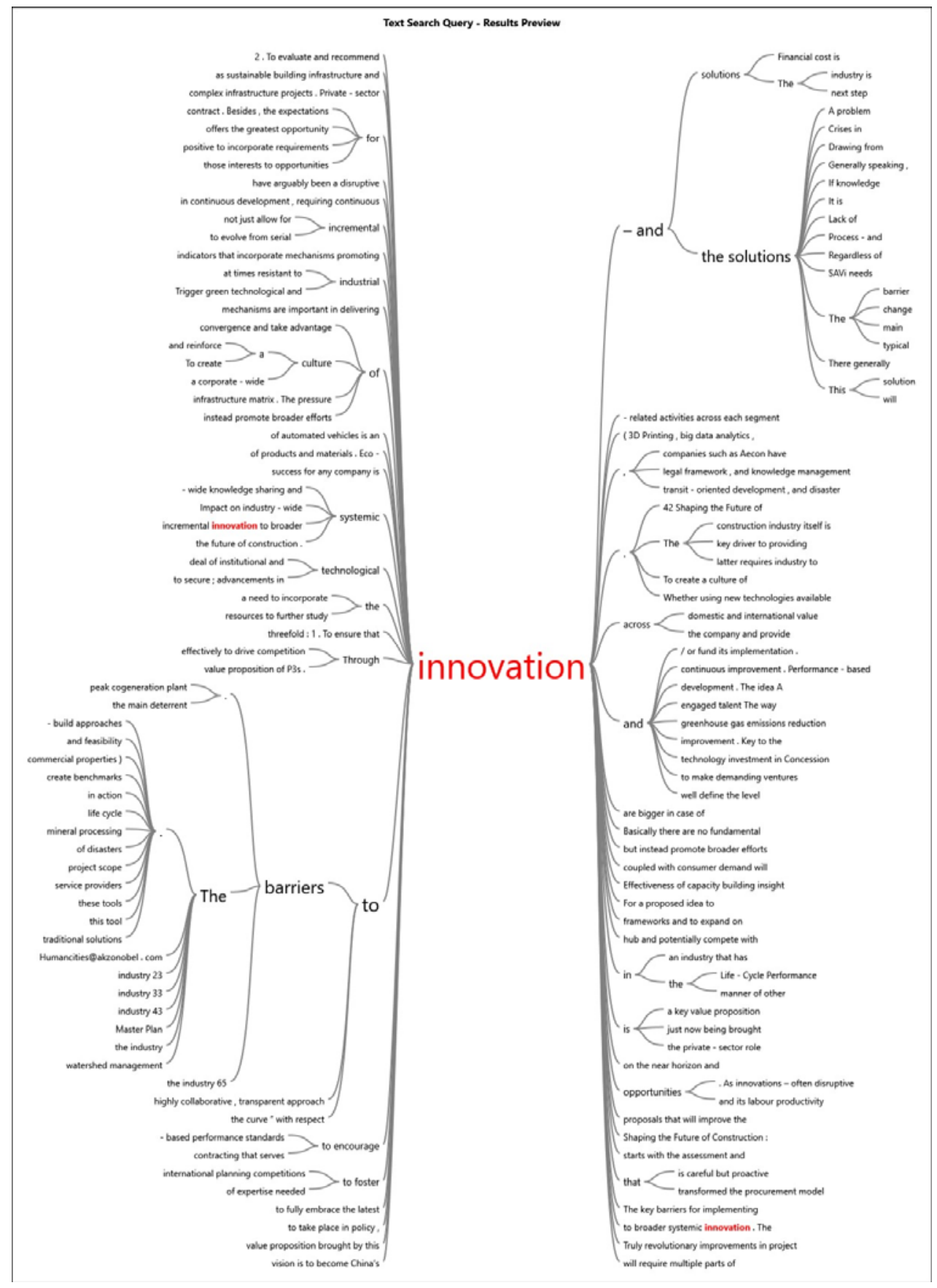

Figure 3: Word Tree for the Word "Innovation" 
To consolidate key themes and their relationships reached from the initial themes, nodes can be visualized using cluster analysis. As an exploratory technique, cluster analysis diagrams provide a graphical representation of nodes to demonstrate similarities and differences. Nodes in the cluster analysis diagram that appear close together are more similar than those that are far apart. Grouping of nodes is based on the ratio of sharing similar words and coded similarly. For this study, a horizontal dendrogram type is used for cluster analysis, which is a horizontal branching diagram. Also, items clustered using Pearson correlation coefficient that is one of the offered similarity metrics by NVivo. When the horizontal dendrogram (Figure 4) is examined, similar themes are clustered together on the same branch and shown with similar colors, such as "Lessons learned" and "Value engineering".

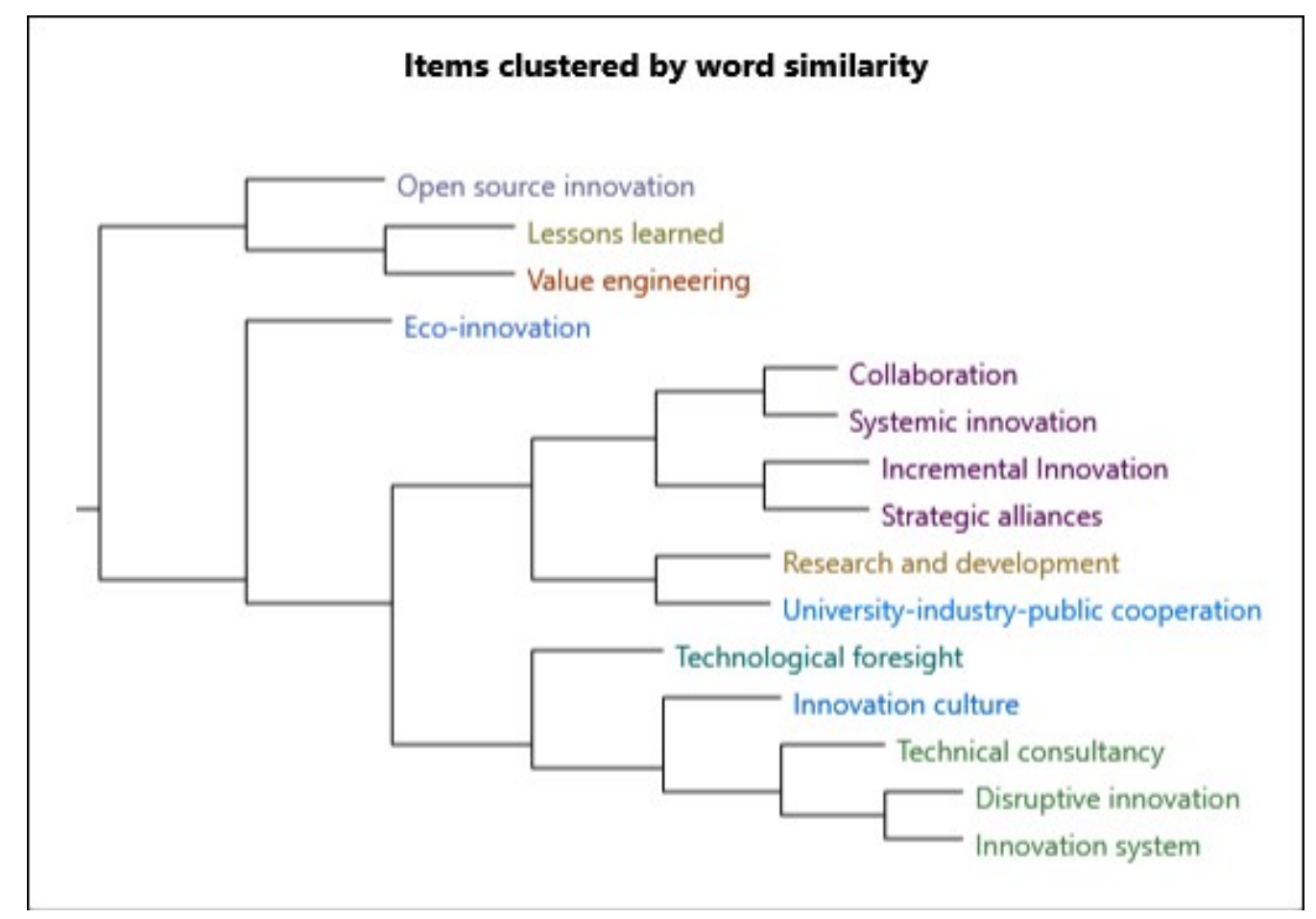

Figure 2: Items Clustered by Word Similarity

When the main themes and their relationships are created, a comparison diagram is created using NVivo comparison diagrams feature. The diagram is used to compare two of the same type of project items to see their similarities and differences. In this case, the WEF Report and SPTC are the selected cases, and their documents are shown as a pdf file symbol (See Figure 5). Since the themes are assigned as a node, the blue circles represent the assigned nodes. As it is seen in the figure, while similarities are gathered around eight nodes, there are additional seven nodes which is not even mentioned in SPTC. 


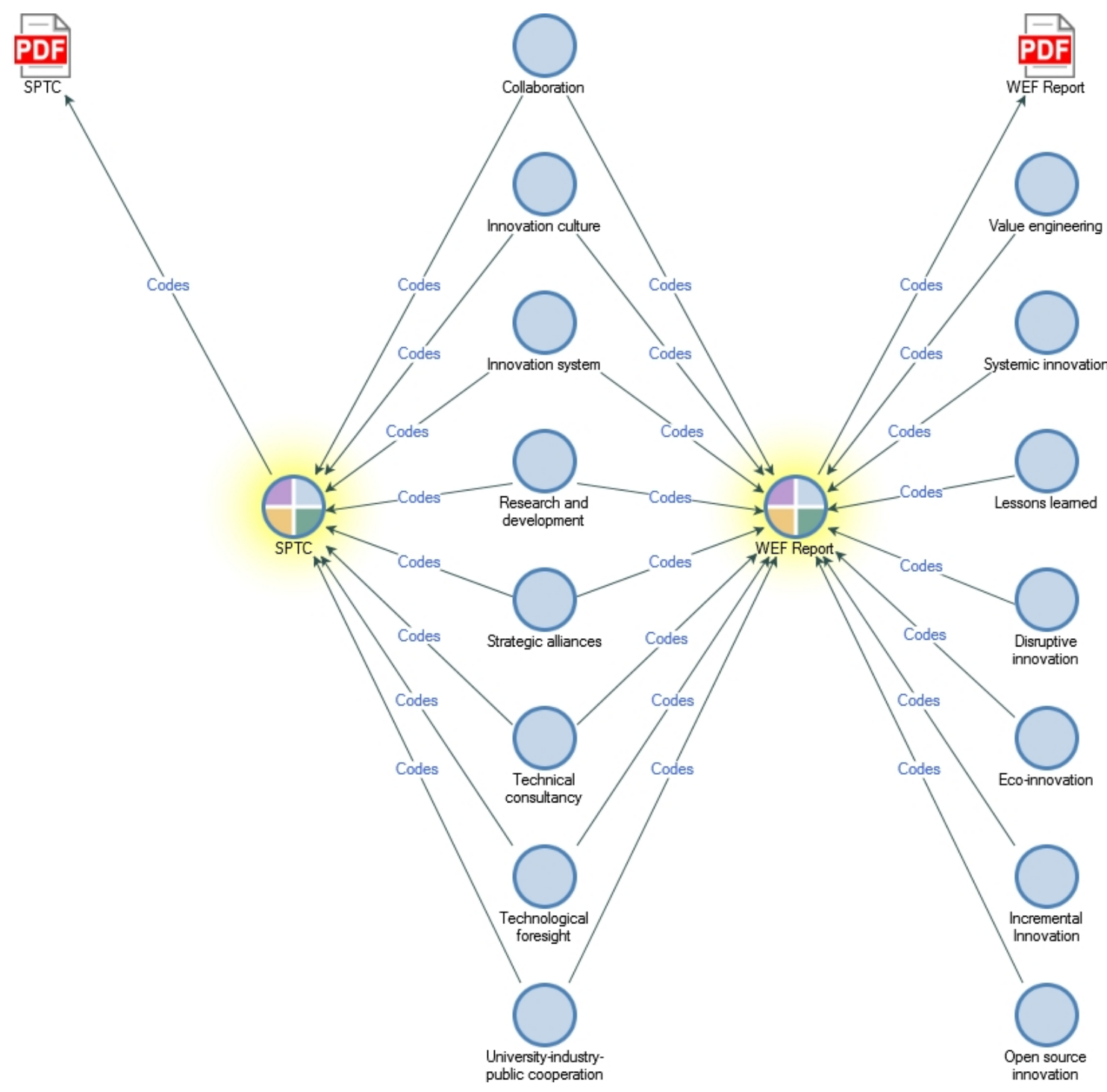

Figure 5: Comparison Diagram

\section{Discussion of Findings}

The main advantage of conducting data analysis using NVivo software is possibility to eliminate human error that would be expected to occur if the comparison were carried out manually. In addition to the human error, biases are eliminated to a certain extent, and this type of data interrogation enhances the overall impression of the data and credibility of the findings.

In this study, the core contents of the WEF Report and SPTC are analyzed and identified. Seventeen themes from WEF Report and eight themes from SPTC are determined. When the comparison diagram is observed given in Figure 3, both SPTC and WEF Report points out the necessity of developing an innovation system for a technology-oriented construction sector. Mutual connections exist between the reports. In this context, both documents recommend to take the following steps:

1. Creating an innovation system

2. Creating/preserving a culture of innovation in the sector

3. Determination of strategic priority research and development activities for the sector (BIMbuilding information modeling, lean construction, sustainability, waste management, etc.)

4. Conducting determination of technological foresight and $R \& D$ agenda as a regular work

5. Establishment of special support programs for the construction sector, and arrangements (incentives, etc.) 
6. Developing public cooperation in order to support the R \& D activities of NGOs

7. Establishment of platforms to improve university-industry-public cooperation in $R \& D$ activities

8. Effective use of existing mechanisms (technology transfer offices, etc.)

9. Creating good practice examples and benchmarking opportunities for the sector

10. Encouraging innovation through the selection of technical consultants based on qualification

As can be seen in the comparison diagram in Figure 3, while different types and novelty degrees of innovations are mentioned in the WEF Report, these subjects are either not referred or mentioned very superficially in SPTC. Key themes mentioned in the WEF Report are value engineering, systemic innovation, lessons learned, disruptive innovation, eco-innovation, incremental innovation, and open source innovation. Value engineering as an organized effort that analyzes the function of a process or a product is expressed in the WEF Report as an innovative solution throughout the life cycle stages of the construction projects in order to achieve affordability. Systemic innovation corresponds to the type of innovation that only generates value if accompanied by complementary innovations. In the WEF Report, it is mentioned as a need to evolve from incremental serial innovation to broader systemic innovation. Systemic innovation is given as a requirement to improve the future of construction. It also requires multiple parts of the industry to transform in tandem. Moreover, an outcome of the comprehensive industry collaboration proposes developing an outline to systemic innovation frameworks. In the WEF Report, consequent developments are needed to take place in policy, innovation, legal framework, and knowledge management and education systems in order to reach the full potential of the industry-wide-transformation. The ability to leverage valuable knowledge and lessons learned to early adopters across the company is mentioned as a factor to reduce redundancy and create process efficiencies. In this sense, the repetition of mistakes is avoided. If the knowledge transfer is to be successful, there must be an openness and richness in the communication of information and knowledge. Crucial knowledge gained from a project is not always documented and added value of lessons learned is not widely recognized as a contributing factor to project success. The WEF Report mentions that methods for evaluating and measuring the effectiveness of the life cycle lessons-learned program are needed to be established since it helps management to monitor, improve and illustrate the value that lessons learned provide to the life cycle. Furthermore, the WEF Report expresses that all relevant stakeholders need to communicate with external stakeholders to reach a common understanding about value, and all should be able to access lessons learned. Disruptive innovation helps to create a new market and value network and eventually goes on to disrupt an existing one. This innovation type is also referred in WEF document in which as a disruptive innovation, PPP is introduced as a key concept. In this sense, it is argued as a way of transformation of existing method for delivering large complex infrastructure projects. Eco-innovation, as the development of products or processes that contribute to sustainable development and elicit direct or indirect ecological improvements is another expressed theme in the WEF Report. In the report, the importance of eco-innovation is shown with the assessment and selection of goods and materials that respect people's health and environment, and focusing on sustainability has led to the necessity of eco-innovations. In addition to that, incremental innovation is mentioned as one of the keys to the industry's success. The incremental changes are not an option instead; it should be seen as a key to reach radical goals, out-of-the-box solutions, and executions. Moreover, it is stated that demanding improvements must not just allow for incremental innovation. Further, they should also promote broader efforts of innovation and continuous improvement. Truly revolutionary improvements in project execution need a transformation of the industry. In this sense, not only incremental innovation but also broader systemic innovation is necessary to evolve. As a more radical innovation concept identified as open source, is presented in the WEF Report. Since close innovation is limited to proprietary internal resources, including internal Research and Development, as a general definition, open innovation includes external resources to acquire ideas and skills (Curmi and SammutBonnici, 2015). In this sense, open source innovation is characterized by opening the innovation process and its process that is essential for how stakeholders collaborate on ideas to make them become a reality in a complex project. The significance of open source innovation is to create a huge ecosystem of innovators who are sharing knowledge with others to create new resources instead of competing for scarce resources, which is highlighted in the WEF report. It ca be concluded that WEF report considers different aspects of innovation and proposes more comprehensive strategies to enhance it when compared to SPTC. A richer picture of the innovation system is definitely more beneficial to develop effective strategies. 


\section{Conclusions}

Innovation is a source of competitive advantage. It is a strategic theme mentioned in various roadmaps prepared to foster competitiveness of Turkish contractors in international markets. However, in majority of cases, innovation is considered as a "target" that can be achieved by increasing R\&D expenditure. Moreover, it is highly associated with technological advances and innovation system is not conceptualized and expectations from this system are not well-defined. The aim of this study is to compare innovation as a concept that appears in the strategic plans in Turkey with a global report. Results of a comparative qualitative content analysis of two strategic documents, namely SPTC and WEF reports, are depicted. In SPTC, based on the analysis of the current situation of the Turkish construction industry, several strategies are proposed to enhance competitiveness and to increase the share of the Turkish construction industry in the international markets where "innovation" is identified as a high priority strategic program. In the WEF report, the challenges in the global construction industry are addressed, and the possible solutions to these challenges are proposed considering innovation in a wider perspective. Strategic themes that are not mentioned in SPTC include value management, lessons learned, and systemic, disruptive, incremental, open source and eco-innovation. A wider perspective is needed to formulate strategies to enhance innovation system in the construction industry.

Finally, it is argued that comparative qualitative research can help policy makers to understand the strengths and weaknesses of their strategic plans by comparing it with others. Policymakers can benchmark from other documents and incorporate alternative options and/or themes that would be helpful for their strategic plans. This study presents findings of a specific application, however it has a number of limitations. The two strategic documents that are used to demonstrate how qualitative content analysis may help strategic planning may not be directly comparable as their aims are not exactly the same as well as the dates. Analysis could be carried out considering various similar strategic documents rather than just one global report. The benefit of using content analysis, which is mainly, potential increase in the quality of plans, could not be monitored and validated in this study. Further studies are required to demonstrate potential benefits of utilization of comparative content analysis for preparation of strategic roadmaps.

\section{References}

Curmi, F. and Sammut-Bonnici, T. (2015) 'Innovation Strategy' in Cooper, C. L. (ed.) Wiley Encyclopedia of Management. John Wiley \& Sons, pp.1-5.

Engineering News Record. (2017). [online] Available at: https://www.enr.com/toplists/2016-Top-250International-Contractors1 [Accessed 10 May 2019].

Sammut-Bonnici, T. and Paroutis, S. (2013) 'Developing a dominant logic of strategic innovation', Management Research Review, 36(10), pp. 924-938. doi: 10.1108/MRR-08-2013-0184.

Seaden, G. and Manseau, A. (2001) 'Public policy and construction innovation', Building Research and Information, 29(3), pp. 182-196. doi: 10.1080/09613210010027701.

Sundbo, J. (2002) 'The service economy: Standardisation or customisation?', Service Industries Journal, 22(4), pp. 93-116. doi: 10.1080/714005099.

Turkish Contractors Association (TCA) (2004) Inşaat Sektörü Stratejik Planı. Available at: https://www.tmb.org.tr/arastirma_yayinlar/insaat_sektoru_stratejik_plani_2004.pdf

Turkish Ministry of Development (2014) Onuncu Kalkınma Planı. Ankara. Available at: http://www.sbb.gov.tr/ozel-ihtisas-komisyonu-raporlari/\#1543312172966-b62de4d7-b832.

Türkiye Müteahhitler Birliği. (2004). [online] Available at: https://www.tmb.org.tr/tr/yayinlar/arastirma-veyayinlar/tmb-yayinlari/ [Accessed 22 May 2019].

World Economic Forum (2017) 'Shaping the Future of Construction Insights to redesign the industry', Industry Agenda, (February), $\quad$ p. $96 . \quad$ Available at: http://www3.weforum.org/docs/WEF_Shaping_the_Future_of_Construction_Inspiring_Innovators_redefi ne_the_industry_2017.pdf. 